\title{
THE ROLE OF TEACHERS' VIEWS ON SCHOOL PERFORMANCE IN THEIR TEACHING APPROACH AND THEIR RELATIONSHIPS WITH STUDENTS: THE CASE OF MOUNTAINOUS AREAS AND PERIPHERY SECONDARY SCHOOL TEACHERS IN THE PREFECTURE OF ILIA, GREECE
}

\author{
Eygenia Davou, \\ Natassa Raikou ${ }^{\mathrm{i}}$ \\ Postgraduate Program in Adult Education, \\ Hellenic Open University, \\ Greece
}

\begin{abstract}
:
The present study investigates to what extent teachers serving in mountainous areas and periphery schools consider that their perceptions on factors affecting school performance influence the way they choose their teaching practices and shape their attitudes towards students. In the survey, 133 secondary school teachers of the Prefecture of Ilia answered a questionnaire with closed-ended questions. According to teachers' beliefs, school performance is influenced by socio-economic, educational and geographical factors. It is not associated with intelligence/brilliance and it can be improved with the help of the teaching staff. Teachers' expectations have an effect on their school performance, while the Curricula do not take into account the learning abilities of the students and the school evaluation does not assess the school performance in a meritocratic way. Nevertheless, positive expectations for the performance of weak students are maintained by choosing teaching practices that they believe will enhance their performance.
\end{abstract}

Keywords: teacher beliefs, student teaching, performance assessment, secondary teacher education

\section{Introduction}

In recent years numerous studies appeared in both the international and Greek corpus of bibliography extensively referring to the multifarious factors that interact and form the performance in school and contribute significantly to the collection of useful information and to the overall reflection upon this subject.

i Correspondence: email araikou@upatras.gr 
The compelling studies that were materialized in many countries and a variety of educational environments have enriched and innovated the scientific dialogue, since they investigate variables directly or indirectly related to student performance and look for extra-educational and educational factors that lead some students to excellence and others to failure (Bernstein, 1961; Bourdieu \& Passeron, 1996; Heliou, 1984; IsambertJamati, 1976; Mylonas, 1993, 2004; Papakonstantinou, 1981; Fragoudaki, 1985; Tzani, 2004).

The connection between the school performance, translated as the successful adaptation of students to the dominant educational model, and the socio-economic factors but also the other didactic, learning, pedagogical, processes, constitutes a further difficulty to the investigation of the ways in which this aim is achieved (Fragoudaki, 1985).

Every survey, all over the world, converges on the conclusion that the factor of socio-economic background and poverty contributes significantly to poor school performance, educational deprivation and early school abandonment (Milios, 1993; Tsoukalas, 1992). At the same time, it turns out that children from low-income or nonregular income families whose parents do not have a high level of education, but also children living in remote villages and rural areas, are more likely to be candidates for low school performance and often drop out of school, not even completing the obligatory period of education (Devine, 2004; Desforges \& Abouchaar, 2003; Katsikas \& Kavvadias, 2000). Also, students from non-urban areas or from mountainous areas with limited rates of development, usually record much lower school and general educational performance, compared to students from urban areas with higher development. Data that highlight the fact that the inequality of social dynamics is broadly diffused into the educational process, by means of a selective grouping and categorization of students into "good" and "bad" (Center for Educational Policy Development/KANEP, 2011; Mylonas, 2004).

Since the 1990s, along with the study of extracurricular factors related to school performance (macro-sociological approach), a special interest has been developed by the founders of Pedagogical Science, in order to ascertain up to what degree the teachers' personal beliefs on learning and teaching determine the teaching and pedagogical practices they follow, but also how they affect student performance (micro-sociological approach) (Anderson \& Bird, 1995; Matsagouras, 2006).

The research has shown that the teachers' personal beliefs, meaning the fixed, formal or stereotypical ways in which they perceive teaching, are often internalized by them in an unsystematic and unconscious way and formulate their "personal theory" of teaching (Anderson \& Bird, 1995; Fry, 1984; Nespor, 1987; Pajares, 1992).

More specifically, the teaching decisions the teachers are inclined to take according to personal beliefs about student performance significantly regulate the modalities applied by them to implicate the students in the educational process, determine the support they provide to them and the nature of the interpersonal relationships they 
develop with them in the classroom (Clark \& Peterson, 1986; Fang, 1996; Matsagouras 2001).

Given that the Greek educational system is unequally designed, since it does not take into account the socio-economic-cultural and geographical inequalities (Mylonas, 2004), the question is arisen: whether and to what extent the personal beliefs of teachers in the Secondary Education regarding the factors that shape school performance, lead them to choose specific teaching approaches and form a specific relationship with students (Fives \& Buehl, 2008; Matsagouras, 2004; Pajares, 1992)

\section{Performance and "Socio-economic-educational and geographical factors"}

In school, the notion of the performance constitutes a key component for success or failure, given that it is mainly related to cognitive characteristics and in particular to the acquired knowledge by the student and his ability to use it in various situations (Kassotakis, 2003).

In the Greek educational system, the concept of school performance is directly related to the level in which students of a particular class have achieved the teaching or learning goals and objectives set by the curriculum of various classes (Lappa \& Vardoulis, 2006; Tzani, 2004). School performance is evaluated according to the results of the exams undertaken by the students. The main purpose of the evaluation of the performance is not to record the general individual effort and progress of the students, but also to record the level of learning they have achieved according to some criteria common to everybody, without taking into account the different learning conditions that prevail (Askouni, 2003;

Katsikas \& Kavvadias, 2000; Konstantinou, 2002; Rekalidou, 2011).

Sociological researches carried out en masse since many decades, from 1960 until today, in all western industrialized countries, aiming to identify the main factors that affect the performance of students in school, starting with the classic and much discussed in the international literature study propounded by the American sociologist and thinker James Coleman (1966), entitled "Equality of Educational Opportunity" and better known as the "Coleman Report", reveal the high statistical relevance between school performance and social background (Askouni, 2007) and dispel the strong and widespread ideological concept that the main cause of the school performance is the different individual physical / mental abilities of students (Askouni, 2003; Booth \& Dunn, 1996; Gardner et al., 1996; Coodnow, 1990; Fragoudaki, 1985, 2001).

Following Coleman's theory of "social capital", Bourdieu extended the very concept of capital to the plane of non-economic, intangible cultural capital and with the theory of "cultural capital" brought to the fore another concept, according to which in society the unequal distribution is not extended only to the financial capital, but also to the cultural capital and this differentiation usually works in parallel in the school performance of students (Bourdieu \& Passeron, 1996; Desforges \& Abouchaar, 2003; 
Fernández-Mellizo, \& Martínez-García, 2017; Lampiri-Dimaki \& Panagiotopoulos, 1995; Tzani, 2004).

According to Bourdieu (1966) the cultural capital implies non-financial goods and services that help someone to improve one's social status. It includes knowledge, predispositions and educational resources and competences (language skills, cultural knowledge, ways of thinking and behaving) that the child acquires growing up in a specific family and wider social environment and help him/her to absorb and decode the culture in general and school culture in particular (Booth \& Dunn, 1996; Patereka, 1986). Thus "cultural" inequality in school is translated either in success or failure because the unfamiliarity lower-class students show to the school culture is perceived by their teachers as an evidence of mental inferiority (intelligence racialism), or as an evidence of insufficient effort (Askouni, 2007; Bourdieu \& Passeron, 1996; Lampiri-Dimaki \& Panagiotopoulos, 1995; Tzani, 2004). The discriminating factor in school that considers children with rich "cultural" background as charismatic, "translates the social status into a physical qualification", perpetuating and legitimizing the myth of the "natural gifted" for those students who meet the requirements of school culture (Blackledge, \& Hunt, 2000; Desforges \& Abouchaar, 2003; Kelpanidis, 1997; Tzani, 2004; Fragoudaki, 1985, p. 167).

At the same time, the English sociologist B. Bernstein, who systematically studied the mechanisms and social processes adopted by the school for the transmission of knowledge, is the first in the international literature that correlates, by means of his sociolinguistic theory, school performance with the social origin of the student and the language code he uses (Lamnias, 2002).

He found out that within the school environment coexist students with different socio-linguistic characteristics not identical with those of the "standard-academic" language taught by the school (Bernstein 1961, as cited in Fragoudaki, 1985, p. 117). In his work "Some Sociological Determinants of Perception" (1958) he argues that due to the fact that language is an internalized form of "cultural capital", a fundamental cause of the mass schooling failure for the children is the linguistic difference between the standard language (refined code) the school uses, and the linguistic varieties (limited code) employed by various social stratae (Bernstein, 1961).

Respectively, the researchers linked with the Sociology of Education pinpointed that the geographical origin of the students seemed to play a decisive role in the school performance, since it is demonstrated that differences in student performance depended on the geographical area (village, city, center, region) of the school (Heliou, 1984; Visscher \& Coe, 2003; Sipitanou, 1992; Mylonas, 2004), and children from urban areas and upper cultural classes are seemingly promoted to a greater extent to higher education levels than children from geographically disadvantaged rural areas. 


\section{Performance and teacher's "Personal theory" of teaching}

From extended studies in many branches of Education Sciences (Teaching, Pedagogical Psychology, Sociology of Education) it is understood that each teacher has consciously or unconsciously developed a sum of mental habits that govern his/her actions. In other words, he/she uses his own belief system by means of which he/she interprets a variety of educational issues and which functions as the basis of his "personal theory" (Matsagouras, 2001, 2004; Nespor, 1987; Pajares, 1992; Yero, 2002).

The concept of "personal theory" appears in the pedagogical literature under a variety of terms, such as: "latent theory", "personal, practical knowledge", "intuitive knowledge", "subjective theory", "cognitive patterns", "teacher's theory or views" (Ajzen \& Fishbein, 1972; Kalaitzopoulou, 2001, p.60; Matsagouras, 2006, p.194).

Teachers' "personal theory" contains both general perceptions, beliefs, opinions, values and attitudes related to the aims and role of education, the nature of knowledge and the way of learning, as well as specific ideas related to teaching, students, discipline, the roles and responsibilities of teachers, school performance, textbooks, curriculum content and orientation, assessment, as well as interpersonal communication with students (Clar \& Peterson, 1986; Fives \& Buehl, 2008; Fry, 1984; Kagan, 1992; Pajares, 1992; Weiner, 1994).

Researchers have shown that teachers' "personal theory" on students, their mental abilities, the way they learn, the factors that are responsible or related to school performance, is rigid, is not readily modified and becomes a pattern of behavior that affects the interaction between teacher and student during the teaching practice (Clar \& Peterson, 1986; Cooper, 1985; Fives \& Buehl, 2008; Fry, 1984; Matsagouras, 2001, 2004, 2006).

The teacher's "personal theories" connecting the teaching with school performance (theory of individual mental ability / intelligence, theories of positive and negative expectations on school performance: Pygmalion effect and Golem phenomenon, definition of the framework of teaching by the Curriculum, linking evaluation with student performance), affect the learning outcomes of students to the extent that teachers shape and differentiate their behavior on their basis (Good, 1982; Kossivaki, 1999, p.169; Mylonas \& Dimitriades, 1999, p.395).

The "myth" of intelligence/brightness racism is widespread among teachers and is often contained in their own "personal theory" of teaching. It is mostly expressed in generalizing "constructs" about the role played by intelligence in school performance such as: "students who perform well are smart", "intelligence / brightness leads to school success", "some students are smarter than others", "natural and innate intelligence leads students to school success, the proof and guarantee of which is the possession of school diplomas" (Bourdieu \& Passeron, 1996; Lynott \& Woolfolk, 1994; Matsagouras, 2006).

Often, trapped in the myth of students' mental superiority or inferiority, the teachers are convinced that some children are "literate" and some are not, that the 
student's performance at school is determined by how smart he/she is and that school and themselves are not capable to remedy many things (Brophy \& Cood, 1974). Motivated by their belief in the differentiated intelligence, they overlook the fact that human mental abilities are "infinitely adaptable to the physical and social environment and also infinitely evolving" (Askouni, 2007; Bourdieu, 1999, p. 87; Fragoudaki, 1985, pp. 166-167). Depending on the case that one student succeeds or on the contrary fails, the teachers tend to attribute this result to the student's low or high intelligence and not to the very institution of school (Bassetas \& Poulou, 2001).

The psycho- pedagogical theory that describes the positive effect teachers' expectations can have on students' performance is generally acknowledged in the bibliography as the "Pygmalion effect or result." The most eminent research on the functioning of teachers' expectations is the one undertaken by Rosenthal and Jacobson (1968), who first noted, in their book "Pygmalion in the classroom", that children for whom teachers had positive expectations and prejudices about their progress they actually made the expected progress (Brophy \& Cood, 1974; Niari, 2013; Rist 2000). In particular, the students for whom the teachers expected to make significant progress in their performance, significantly outperformed other students (Boser, et al., 2014; Chang, 2011; Bassetas, 1999; Pyrgiotakis, 2006; Reynolds, 2007; Sprouse \& Webb, 1994; Reynolds, 2007; Trouilloud \& Sarrazin, 2003).

Most teachers tend to differentiate in the teaching process their behavior towards the "good" and "bad" students in the classroom, often make predictions about their future (Cooper, 1982; Good, 1982) and attribute the successes of the "good" students and the failures of the "bad" ones mainly in individual factors, such as their intelligence, diligence and skills (Bassetas, 1999, 2010; Pyrgiotakis, 2006 p. 308).

To the role of expectations in the educational process and the way in which they affect learning behavior is also referred the psychological "Golem Phenomenon", which is a negative version of the Pygmalion Phenomenon and explains the importance the discouragement and low or negative expectations have in the performance of individuals (Chang, 2011; Kostaridou - Efklides, 1999; Reynolds, 2007; Trouilloud \& Sarrazin, 2003). According to the Golem Phenomenon, students react to the low-negative expectations their teachers communicate and try to become compatible with them, showing low performance. This is happening because teachers are considered as important people ("important others") to the students and the impact of the negative expectations on them is stronger, due to the emotional closeness between them (Katsillis \& Lolou, 1999; Kelpanidis 1997; Pyrgiotakis, 2006).

The teaching practice used by teachers in order for their students to achieve and attain the desired objectives of their class lessons, has been shown to be influenced by the way teachers perceive and interpret the Curriculum (Matsagouras, 2006; Koutselini \& Pyrgiotakis, 2015). The Macro-level Curriculum (philosophy, rationale, educational objectives) is one of the "framework factors" (regulatory, normative, social, philosophical and ideological texts) that mediate between teachers' "personal teaching theory" and 
educational practice. Teachers tend to implement educational policies when they agree with them or when they consider that they are institutionally obliged as educators to implement them, in order to be productive to the extent envisioned by the designers of the Curriculum (Matsagouras, 2001; Bagakis, 2004).

In these cases, the "personal theory" of teachers is based on the belief that the role of the teacher is practical and that the skills he must have are those of a competent manager of the teaching process, the performer of a prescribed teaching and learning process and the specialist technocrat, who has the ability to transmit a package of knowledge to the student and at the same time to evaluate-measure his performance (Noutsos, 2003). In other words, the teacher literally executes the instructions of the Curriculum to every issue related to teaching and learning, without taking into account the different social, economic, educational capital of students, their degree of readiness and the conditions for improvement of their performance (Feinberg, \& Soltis, 1992; Koutselini, 2008).

In the educational literature corpus is manifested that there is an interaction between teachers' beliefs about the way and methods by which performance is assessed and the evaluation procedures they apply themselves in the classroom (Dimitropoulos, 2007). Meaning that the way teachers perceive evaluation also affects the way they apply it for the evaluation of their students (Sharp, \& Green, 1978; Xochellis, 2000, 2005).

The way in which teachers expound evaluative judgments for the students and their positive or negative grading, contribute decisively to the pedagogical communication between them (Georgiou et al., 2002, p.115). Studies have shown that students who face difficulties, that is to say the "bad" or "weak" students, are ignored by the teacher, accept derogatory descriptions such as "worst", "inferior", "last" student, treated with leniency or rejection, are excluded from classroom activities, while teachers' demands on them are reduced (Vaikousi-Vergidou, 1994). Teachers express their positive expectations towards students with good grades and with supportive and guiding behavior, while students interpret good grades as a sign of love and the bad ones as negative criticism or as personal rejection (Konstantinou, 2002).

\section{Educational intervention}

\subsection{Aim - Objectives - Research Questions of the study}

The aim of the present study is to investigate to what extent the teachers of mountainous areas and periphery secondary schools in the Prefecture of Ilia in Greece consider that their perceptions of factors that affect student performance might influence the modalities they adopt for their teaching practices and shape their attitude towards students.

The objectives of the research as they are identified / specialized in the framework of the aforementioned aim are: 
1) To investigate the degree of connection the teachers of Secondary Education of the Prefecture of Ilia make between school performance and socio-economic factors.

2) To highlight the extent to which the teachers of Secondary Education of the Prefecture of Ilia correlate the influence of educational and geographical factors with the school performance.

3) To discover the range of recognition the Secondary Education teachers of the Prefecture of Ilia extend to the beliefs that constitute their "personal theory", guiding their teaching practices and relationships with students both on an individual or group level.

\subsection{Research design and methodological tool}

\subsubsection{Research strategy and survey plan}

In order to achieve the goal of the present study, a contemporary research project was selected in order to collect quantitative data from teachers of mountainous areas and periphery secondary schools in the prefecture of Ilia, regarding their personal beliefs on the school performance of students (both male and female) and their role in didactic approaches and relations with the students. The quantitative strategy, as a systematic and standardized method of measurement, allowed the interpretation of teachers' views in an objective way, without the influence of the interference of personal values and attitudes of the researcher (Bryman, 2018).

\subsubsection{Data collection tool}

For the elaboration of the present study, a suitably structured individual completion questionnaire was selected as methodological tool for data collection (five-point Likert scale with options from 1 to 5 - strongly disagree, disagree, neither agree nor disagree, rather agree, strongly agree) which included three (3) distinct parts / fields and contained 82 closed-ended questions only.

At the beginning an introductory letter was handed that contained the personal data of the researcher, expounded the purpose of the survey, explained the reason for the necessity the form should be completed and returned, assured the anonymity and confidentiality of the answers, informed about the required time period for its completion and the timeline to be handed over to the researcher (Cohen \& Manion, 1997, pp. 97-98, Creswell, 2016).

The first part included a table to be filled with the data referring to the individual and demographic features of the respondents. In the second part there were proposed statements divided into three axes, the first of which corresponded to the factors that affect the school performance of students of both sexes, the second corresponded to selected personal beliefs of teachers about school performance and the third to the way these beliefs affect their teaching practice and the relationships they develop with students. 


\subsection{Reliability - Validity of the survey}

To ensure the fidelity to the measurements, we tried the questions of the questionnaire to be targeted and structured appropriately, in order to achieve a stable research course, without particular deviations. We made sure that the questions were formulated clearly and we opted for the process of providing the questionnaire to the participants to be standardized, in order for the measurement to yield consistent results and thus minimize the possibility of unreliability. In order not to undermine the reliability of the research, we ensured that the participants had enough time to complete the questionnaire, so as to avoid being tired and the questions, thus, to be misinterpreted. In addition, an attempt was made to detail the research procedures we followed, so that it would be possible for another researcher to repeat the research in order to reaffirm the findings (Bryman, 2018). To ensure the validity of the measurement tool we examined whether the content of the questionnaire statements conceptually covers the range of the counted concepts (content validity) and whether the content of the statements is conceptually related to what it intends to measure (apparent validity, Creswell, 2016). For this reason, a record was made of the data / elements referring to each concept, so that they are examined in each statement of the questionnaire and an attempt was made to measure all its dimensions, as identified in the conceptual definitions (Bryman, 2018).

Following, the content of the questionnaire was given for evaluation to a specialist (supervising teacher), to judge the design of the questions, the extent to which the questions included in the study duly represent the field under study, whether the questions are the appropriate for what we want to measure or whether significant data have been omitted or included irrelevantly (Robson, 2010).

\subsection{Study sample}

The target population of the research included teachers of Secondary education of the Prefecture of Ilia in Greece. The sample was drawn from the teachers of 20 periphery and mountainous areas secondary schools of the prefecture of Ilia (out of a total of 40) and more specifically from the municipalities of Ancient Olympia, Andritsaina / Krestena, Zacharo, Pinios, Andravida-Kyllini and the region of the Municipalities of Ilida and Pyrgos, which among them included also 21 directors and two deputy directors.

The prefecture of Ilia is characterized as an agricultural-livestock territory covering an area of 2,619 sq. km, located in the northwest of the Peloponnese and has a population of 159,300 inhabitants. The schools the research teachers serve are located in municipal or community districts with less than 2,000 permanent residents, in a distance of 20 to 60 kilometers from the two major urban centers of the prefecture--Pyrgos and Amaliada (EL.STAT., 2011).

The researcher's questionnaire was received by 145 teachers of both sexes (convenient sampling/ convenience sample/ no probabilistic), who stated their willingness or disponibility to participate in the research (Robson, 2010). 
The quantitative data were finally obtained from 133 (out of 145) answered questionnaires (response rate 91.72\%) which were handed by the teachers (105 permanent and 28 deputies) who were included in the sample under study. In these questionnaires was depicted a demographic diversity in terms of gender, age, years of service, area and type of school of teacher service (Tables 1 \& 2).

Table 1: Demographic characteristics of the sample $(\mathrm{N}=133)$

\begin{tabular}{|l|l|c|c|}
\hline & & Frequency (N) & Percentage (\%) \\
\hline \multirow{3}{*}{ Gender } & Man & 57 & 42,9 \\
\cline { 2 - 4 } & Woman & 76 & 57,1 \\
\hline \multirow{3}{*}{ Studies } & First degree & 80 & 60,2 \\
\cline { 2 - 4 } & Second Degree & 11 & 8,3 \\
\cline { 2 - 4 } & Master Degree & 42 & 31,6 \\
\hline
\end{tabular}

Table 2: Occupational characteristics of the sample $(\mathrm{N}=133)$

\begin{tabular}{|l|l|c|c|}
\hline \multirow{4}{*}{ Years of service } & & Frequency (N) & Percentage (\%) \\
\hline \multirow{5}{*}{ Occupational relationship } & $0-5$ & 13 & 9,8 \\
\cline { 2 - 4 } & $6-10$ & 14 & 10,5 \\
\cline { 2 - 4 } & $11-15$ & 43 & 32,3 \\
\cline { 2 - 4 } & $16-20$ & 36 & 27,1 \\
\cline { 2 - 4 } & $21-25$ & 14 & 10,5 \\
\cline { 2 - 4 } & Over 26 & 13 & 9,8 \\
\hline \multirow{3}{*}{ School unit of service type } & Permanent & 105 & 78,9 \\
\cline { 2 - 4 } & Substitute & 28 & 21,1 \\
\hline \multirow{2}{*}{ Responsibilities post } & High School & 62 & 53,4 \\
\cline { 2 - 4 } & Technical High School & 110 & 86,6 \\
\hline & Teacher & 2 & 1,5 \\
\cline { 2 - 4 } & Vice Principal & & \\
\hline
\end{tabular}

\section{Survey Findings}

Teachers' views and beliefs about school performance, which are reflected in the results of the present research, are indicators for the interpretation of the teaching practices they adopt and the relationships they develop with their students. The analysis of the results shows that most teachers express the belief that school performance is related both to the social background of (male and female) students, and to the financial situation of their family (Table 3). According to them, both male and female students with lower social status are more likely to perform poorly, whereas students coming from families with high financial capital are more likely to perform highly. This result converges with the findings of the international and domestic literature, which, with only minor differences, showed the relevance between school performance and socio-economic background of the student (Giavrimis \& Papanis, 2008; Giavrimis et al., 2011; Zapanioti, 2019; Kelmali, 2015; Lykidi, 2012; Xochellis, 2000; Sotiropoulou, 1998; Flouris, 2019; Frangoulis 2008). 
Teachers do not correlate school performance with the profession of the parents of the students, as they disagree with the view that children of farmers and manual workers have poor school performance and children of non-manual workers have high school performance. This result deviates from the findings of other studies (Heliou, 1984; Mylonas, 1993; Kelmali, 2015; Fragoudaki, 2001).

There is a large percentage of teachers who express the belief that there is a connection between school performance and the cultural capital of his / her student's family. They believe that the unequal distribution and diversification of students' cultural capital affects school failure or success. In their opinion, the children of educated parents show high performance, because they are familiar with the dominant culture and were granted cultural "endowments" from their family (contacts with theater, literature, museums), in contrast to the children of lower social strata which are characterized by cultural lag. This finding is also detected in several other surveys (Georgiou et al., 2002; Georgiou \& Tourva, 2006; Zapanioti, 2019; Kelmali, 2015; Sotiropoulou, 1998; Flouris, 2019; Frangoulis 2008).

The organizational / functional weaknesses of the educational system, the limited financial support of the schools and the lack of educational infrastructure are considered, according to the findings of the present study, as main factors that affect the school performance (Vaikousi-Vergidou, 1994; Georgiou et al., 2002; Georgiou \& Tourva, 2006; Giavrimis \& Papanis, 2008; Giavrimis et al., 2011; Kelmali, 2015; Poimenidou, 2009; Flouris, 2019) as well as the difficulties of some class courses, the demanding objectives of the curricula, as well as the ineffective educational policy (Kelmali, 2015; Flouris, 2019). The language code of the social class to which the students belong, but also of the area in which they live, are also considered by the educational staff as determining factors that affect the school performance. They report that students who by virtue of their family's status are familiar with the elaborated language code and school culture have a high performance, whereas students who are not familiar due to family reasons with the academic language of the school have a low performance (Zapanioti, 2019; Kelmali, 2015; Sotiropoulou, 1998; Frangoulis, 2008).

Teachers express the view that the work of the teaching staff holds no responsibility for the low performance of students, a finding that is also affirmed in the research of Georgiou et al., (2002), Georgiou and Tourva (2006), Giavrimis and Papanis (2008), Katsamagou (2003), Kelmali (2015), Poimenidou (2009) while they are not sure that their work is associated with high performance, in contrast to the teachers participating in the aforementioned studies, who linked the high performance of students with their work ("self-serving bias").

Many educators believe that there is a direct correlation between students' performance and their place of geographical origin and residence, as they point out that poor performance often have students who live in economically deprived and culturally disadvantaged areas and have difficulty moving to and from school, something also 
confirmed by the results of other studies (Heliou, 1984; Brouzos, 1999; Mylonas, 1993, 2004; Kossivaki, 1999; Lariou - Drettaki, 1993).

Table 3: Influence of the socio-economic and geographical factors on school performance

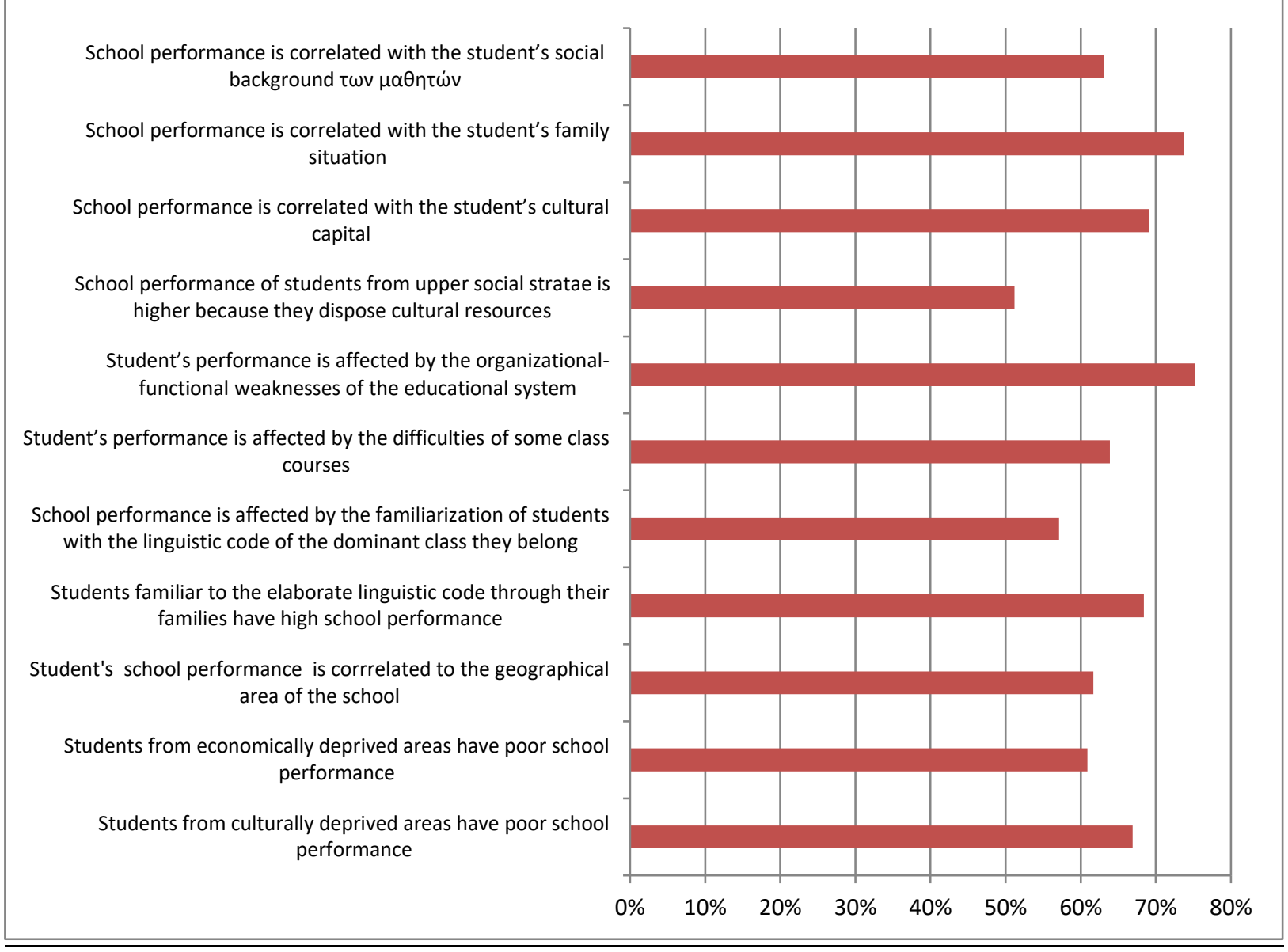

As regards the connection of school performance with the intelligence / brightness of students a large percentage of the interviewed staff are convinced that student performance (high or low) is not a consequence of innate / inherited predisposed abilities, unlike the interviewed teachers who respond to the surveys of Kelmali (2015), Pagoni, (2016) and Xochellis (2000), who correlate student performance with biological or genetic factors.

As for the expectations expressed by teachers for the performance of students, the results of the study show that many of them are convinced that they are able to predict the performance of students early and that, in the end, their predictions are confirmed (Table 4). Almost everyone thinks that every time they express negative expectations about student performance or label a "bad student", the performance of students is negatively affected, whereas if the expressed expectations about what students can achieve are positive, the opposite happens.

In addition, teachers believe that positive expectations (success expectations) enhance the motivation of students to perform, while negative ones weaken it. Findings 
that show that teachers' expectations have a profound influence on students' learning behavior are also found in other studies presented in the context of the review of the corresponding literature (Vaikousi-Vergidou, 1994; Vareltzi \& Giavrimis, 2018; Bassetas, 1999; Lykidi, 2012; Poimenidou 2009).

As regards the way in which the content and the centrally defined teaching objectives of the curricula affect school performance, almost the totality of the teachers expressed the belief that the common curricula do not take into account the learning abilities of the students and do not provide equal educational opportunities to them. This finding is consistent with the results of many other studies (Vaikousi-Vergidou, 1994; Vareltzi \& Giavrimis, 2018; Kelmali, 2015; Poimenidou, 2009).

Regarding teachers' views on school evaluation, it appears that the teaching staff do not share the view that grades control school performance in a meritorious way, nor the view that negative grades can serve as a means of improving the performance of weaker students (Kassotakis, 2003, 2013; Xochellis, 2000, 2005).

Table 4: Teachers' personal beliefs on school performance

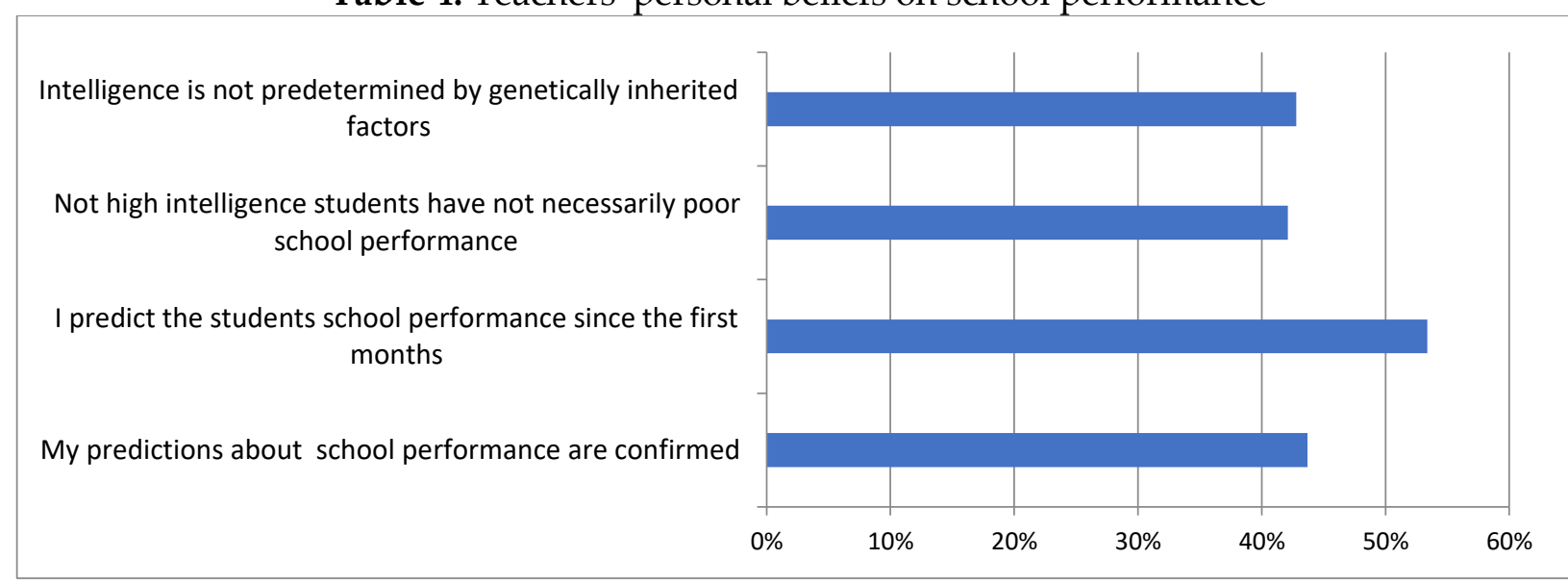

As regards the degree of influence their personal beliefs hold on their teaching practices, and on the relationships, they develop with students, teachers seem to be supportive of weak students. It turns out that teachers do not have low expectations for the performance of their weaker students, in contrast to teachers participating in the Bassetta (1999) study who express negative expectations on the performance of "bad" students. It seems that almost all the teachers in the present study are willing to offer to the weaker students' opportunities to participate, they involve them in groupcollaborative activities, they try to explain the lesson in simpler words and allow them more time to answer the questions (Table 5). Many teachers state that they offer as much teaching support as they need to the weaker students in order to keep up with the rest of the class and nurture reduced demands on them because they find the Curriculum goals demanding. We find that some of the above supportive educational practices also chosen by the participants in the survey of Lykidi (2012), Frangoulis (2008) and Poimenidou (2009), while the teachers who respond to the research of Vaikousi-Vergidou (1994) seem 
not to be interested in weaker students because they feel they are wasting valuable teaching time with them.

Of particular interest are the findings on the way teachers treat their students. Although the research sample is heterogeneous in terms of demographics and job characteristics, almost all teachers affirm that they encourage weaker students in order to improve their performance and that they reward them regardless of the result of the effort they make. The teachers who participate in the research of Frangoulis (2008) have a similar attitude towards the weak students, while the teachers who participate in the research of Vaikousi-Vergidou (1994) seem to put the weak students on the sidelines of the educational process and have negative, derogatory, indifferent, belittling behavior towards them. In the present study, many teachers state that they do not distinguish students between "good" and "bad" on the basis of their learning competence and argue that they do not communicate more with good students in the classroom.

Table 5: Influence of teacher's beliefs on the teaching practices and their relationships with students

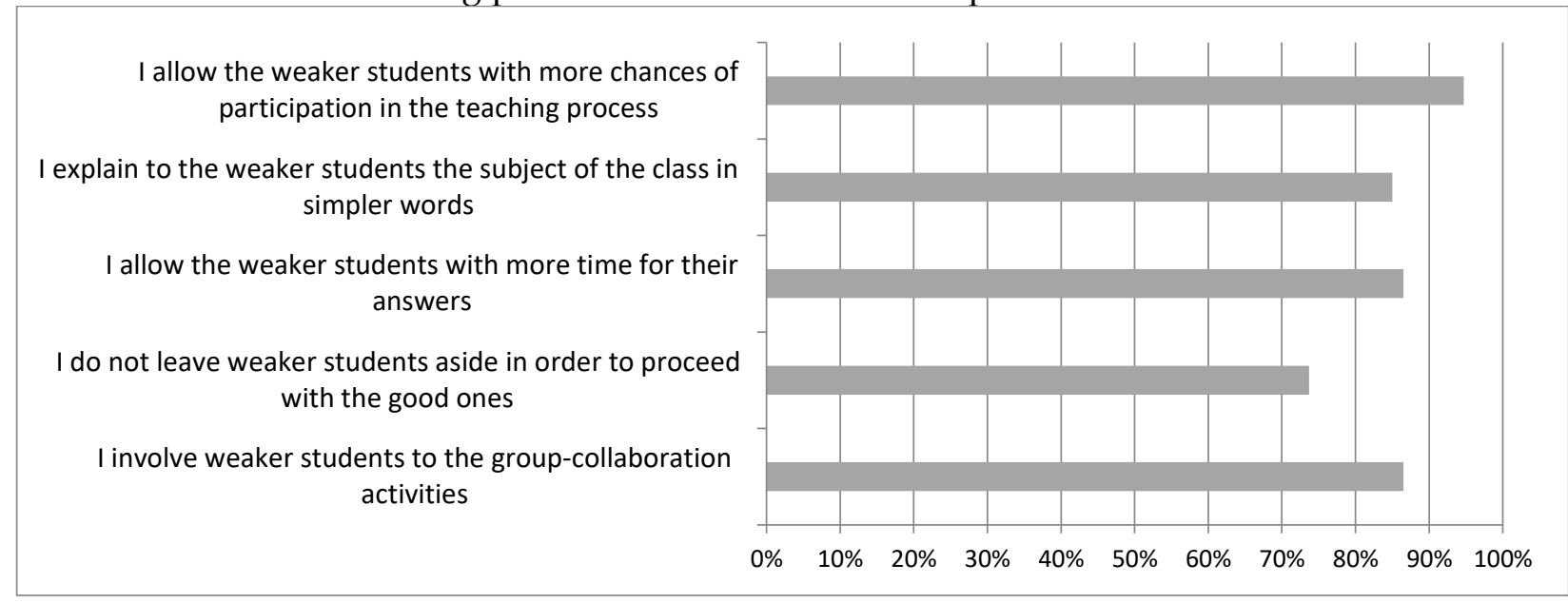

As regards the influence of socio-economic and geographical factors on the school performance of students by virtue of their demographic and work characteristics, teachers' views differ as follows:

- Male teachers, although fewer than women, are more likely to express the belief that school performance (low or high) is greatly influenced by the cultural capital of the family from which the students come and by the level of education of their parents.

- Substitute teachers, although fewer in number than permanent teachers, are more in agreement with the view that school performance is affected by the financial capital of the student's family, school environment, geographical location of the school and organizational and functional weaknesses of the education system.

- Teachers who do not have a position of responsibility express to a greater extent than those who serve as principals / deputy principals the belief that school performance is affected by the cultural capital of students and that high 
performance is achieved by students from upper socio-economic backgrounds, because they adapt more easily to school culture.

- Those who serve in Lyceums sustain to a greater extent than those who serve in High Schools (Gymnasiums) that the work of teachers is responsible for high school performance.

- Teachers with at least 20 years of service tend to disagree more with the view that students from upper social strata perform better than the teachers with 10 years of service.

Regarding the influence of their beliefs on school performance in their teaching practices and in the relationships they develop with students in relation to their demographic and work characteristics, in the views of teachers were observed the following differences:

- Female teachers are more inclined than men to believe that the performance of weak students can be improved. Teachers with a master's degree disagree to a greater extent than those with only a bachelor's or second degree with the opinion that intelligence is innate, genetically predetermined by hereditary factors, and that high or low performance of students is due to innate abilities.

- Permanent teachers generally have lower expectations for the performance of the weaker students, while the substitute teachers sustain to a greater extent than the permanent ones that they devote as much teaching support as the weaker students need in order to keep up with the rest of the class.

- Teachers serving in Lyceums are more likely than High School teachers to believe that the performance of weak students can be improved with the help of the teachers and that the teacher's labelling of a student as "bad" can negatively affect his/her performance.

- It is ascertained that the teachers at the mountainous areas schools have a more positive attitude towards the weaker students than the ones serving in periphery ones, since they do not avoid communicating with them in the classroom and explaining the lesson to them in simpler words.

\section{Conclusions}

The pedagogical beliefs the teachers who serve in the mountainous areas and periphery schools of the Prefecture of Ilia nurture on the school performance reflect subjective experiences from both their personal and professional life. Their composition consists of a network of perceptions and assumptions about school performance and serve as "filters" on a basis of which they interpret the pedagogical framework and select their own teaching practices.

What is recognized by the teachers is that school performance is not a question that merely concerns education, but is also determined by the social and cultural profile of students and constitute the expression of the general belief that the socially defined 
unequal performance could not be removed by the "formal" equality provided by the institution of education, as the language, culture, special learning abilities and geographical backgrounds of the students are not fully recognized as contributing factors. They also admit that the expectations they express on their student's performance can affect their school performance accordingly. They maintain positive expectations from weaker students and believe that school performance can be improved with the assistance of the teachers.

The approach of the school performance in terms of social determinism, the belief that the institution of education reproduces social inequalities and the awareness that their expectations affect the school performance of students (male and female) accordingly, lead them to opt, consciously or not, for reinforced teaching practices and demonstrate an encouraging attitude towards weaker students. The practices they adopt in order to support the weaker students seemingly derive from their structured inclinations for the factors that affect school performance; thus, there is an agreement between what they think and what they do.

We could readily affirm that the teachers participating in the present research perceive the educational process as a dialectical relationship of the macro- and microsociological space, throughout which the teacher by adopting the appropriate didactic approach and attitude can take advantage of the potential of the "non privileged", socially and educationally, students. However, it has been proven that the differentiated teaching practices were not proven adequate enough to enhance school performance, if the context, in which the school operates and students experience educational inequalities, is not taken into account and differentiated (Brookfield, 1995, 2005, 2012).

In order for the teachers' practical knowledge and personal experience to become usable and not abstract and unsystematized, it is necessary for them to be transformed into critically minded professionals who seek to identify, re-examine and judge their perceptions and practices in order to improve and change them (Mezirow, 1998, 2009). Reflective teachers usually combine reflection and action, they persistently and systematically examine every belief or presumed type of knowledge, make a constant critical analysis of their teaching practice, interrogate on their teaching choices, explore the assumptions and implications of their teaching practices and correlate the pedagogical phenomena with the school and social context. In this way, by exploiting also the practical knowledge they acquire through their experience, they gradually discover their choices, decisions and the way they work (Brookfield, 1995, 2005, 2012).

Given that no pedagogical theory that applies perfectly to multifarious educational settings can be ever produced, nor a single correct teaching method can be proposed, every single reflection on education is meant to be considered crucial in order to identify, analyze and solve complex problems that arise in the educational process, but also for the approach of everyday unforeseen and problematic situations the treatment of which is not feasible through technical and scientific knowledge. 
Freire $(1970,1977,1985,1997)$ argues that teachers should not be treated as if they were skilled technicians aware of their subject matter and dispose a repertoire of answers to the didactic questions, but as cultural workers and intellectual reformers who contemplate, wonder, examine and experiment. They should therefore dispose of the necessary scientific and pedagogical training to evaluate their action and its results, to analyze the learning needs of their students and to act accordingly. In the open and constantly evolving field of educational action, the educational process that pursues a critical and contemplative empowerment might help the teachers not to approach teaching merely in an empiric or technocratic manner but would lead them to transform into a "radical" educational action the variety of pedagogical theories they draw in Freire (1970, 1977, 1985,1997).

The training process by which knowledge is conveyed through reflection on the development of a teaching practice and the evolution of the educational practice, orientates the teacher to an interventional practice with the aim, if not the removal at least the management of any restrictions set by the educational framework (Day, 1999; Jarvis, 2001). The educational activities that involve teachers in a process of reflection-reflection on the educational practice, help them to interpret their teaching choices, their personal educational theory, the established practices that determine the educational practice and, after relating them to the social, cultural educational framework, to reform them (Jarvis, 2001).

\subsection{Research limitations and suggestions}

It is not claimed that the results of this research should be generalised. Nevertheless, the fact that the teaching staff in the educational district of the mountainous areas and periphery schools of Northern Ilia (former B and C educational districts) has relatively "permanent" working conditions, we are inclined to believe that it constitutes a rather reliable record of the teachers' views.

The quantitative method, which was chosen as a research strategy, helped to record and investigate the views of a large number of teachers serving in mountainous areas and periphery secondary schools in the prefecture of Ilia. In the survey participated and answered 133 from the 485 teachers who serve in these schools, according to data from the Secondary Education of the Prefecture of Ilia.

It would be useful to have included in our method the interview, alongside the questionnaire, in order to explore teachers' views in depth, as participants would be more likely to provide retractable rather than identifying answers, as is the case with surveys that use only quantitative methods. We could also use "research practice observation" as a research method to identify the interactions that develop between teacher and student. However, both the interview and the observation were difficult to carry out in these schools, because it would have certainly taken a much longer period to complete the research, due to the long distances between the schools and the difficult road network. 
In this context, despite the participation of the majority of teachers from mountain areas and periphery schools of Northern Ilia, the prospect of a generalization of the results of this research should not be considered as certain, since these results concern a specific educational region of the Prefecture of Ilia. The results obtained reflect the sample population of the research and may have varied in case the sample changed or was conducted in a wider educational environment. Possibly the teachers of periphery or mountainous areas schools in other regions of the country express opinions in different degrees on the way socio-economic, cultural and geographical factors influence the school performance, than the teachers of the mountainous areas and periphery schools of Northern Ilia. Furthermore, their views may have differed as regards the extent to which they hold that their beliefs about school performance influence the teaching practices they choose and their relationships with their students.

Regarding our proposals for conducting further research, we would consider it useful to conduct relevant research with a panHellenic representative sample. In addition, it would be interesting to monitor and study the perceptions of the teachers of the specific school units in the long run, in order to see how their data would differ from those that emerged from this research.

\section{Conflict of Interest Statement}

The authors declare no conflicts of interest.

\section{About the Authors}

Eygenia Davou, Med. in Adult Education, Secondary School Teacher in Greek Literature. Dr. Natassa Raikou, Teaching Staff in Adult and Higher Education, University of Patras \& Hellenic Open University, Greece.

\section{References}

Ajzen, I. \& Fishbein, M. (1972). Attitudes and normative beliefs as factors influencing behavioral intentions, Journal of Personality and Social Psychology 21(1), 1-9. http://dx.doi.org/10.1037/h0031930.

Anderson, L. M. \& Bird, T. (1995). How Three Prospective Teachers Construed Three Cases of Teaching. Michigan State University, College of Education: NCRTL Publications. From http://education.msu.edu/NCRTL/PDFs/NCRTL/Research Reports/Rr943.pdf.

Askouni, N. (2003). Social inequalities in school (In the series: "Keys and anti-keys" by Androussou, A. Program "Education of Muslim children"). Athens: YPEPTHUniversity of Athens. Retrieved 21-11-19, from http://www.kleidiakaiantikleidia.net. (in Greek) 
Askouni, N. (2007). Socio-cultural context of education: Social inequalities in education. Athens: Ministry of Education, University of Athens. (in Greek)

Bagakis, G. (2004). The teacher and the curriculum. Athens: Metaixmio. (in Greek)

Bassetas, K. (1999). "The teacher's negative expectations for students' abilities as a cause of school failure and social exclusion." Proceedings of the 5th International Scientific Conference "School Failure and Social Exclusion: Causes, Consequences and Coping" (Ioannina, October 17-19). Athens: Hellenic Letters, pp. 181-199. (in Greek)

Bassetas, K. (2010). Teachers' expectations and their effects on students. Athens: Grigoris. (in Greek)

Bassetas, K. \& Poulou, M. (2001). The attribution of the causes and the assumption of responsibilities by the teachers for the performance of their Students. Pedagogical Review, $32 . \quad$ Retrieved 4-2-20, from https://ojs.lib.uom.gr/index.php/paidagogiki/article/view/6830/6859. (in Greek)

Bernstein, B. (1961). Social class and linguistic development: A theory of social learning. In: A. Fragoudaki, Sociology of Education, Theories for social inequality in school (pp. 393-431). Athens: Papazisi. (in Greek)

Blackledge, D., Hunt, B. (2000). Sociology of Education (English Edition 1985). Athens: Metaichio. (in Greek)

Booth, A. \& Dunn, J. (1996). Family-school links: how do they affect educational outcomes? Mahwah, N.J.: Lawrence Erlbaum.

Boser, U., Wilhelm, M., \& Hanna, R. (2014). The Power of the Pygmalion Effect: Teachers Expectations Strongly Predict College Completion. From: www.eric.ed.gov. No ED 564606 (12/12/2019).

Bourdieu, P., \& Passeron, Cl. (1996). The Heirs. Students and culture (translated by Panagiotopoulos, N., \& Vidali). Athens: Book Institute - Kardamitsa. (in Greek)

Bourdieu, P. (1999). Language and symbolic power. (Translated by Kiki, Kapsabeli). Athens: Kardamitsa. (in Greek)

Brookfield, St. (1995). Becoming a Critically Reflective Teacher. San Francisco: JosseyBass.

Brookfield, St. (2005). The Power of Critical Theory for Adult Learning and Teaching. Open University Press.

Brookfield, S. D. (2012). Teaching for Critical Thinking. San Francisco: Jossey-Bass.

Brophy, J. E., \& Good, T. L. (1974). Teacher-student relationships: Causes and consequences. New York: Holt.

Brouzos, A. (1999). Educational and social exclusion in multi-grade schools: myth and reality. In: Ch. Konstantinou \& G. Pleios (Ed.), School Failure and Social Exclusion, (pp. 263-279). Athens: Greek. (in Greek)

Bryman, A. (2018). Social Research Methods. Oxford: University Press Oxford

Chang, J. (2011). A Case Study of the "Pygmalion Effect": Teacher Expectations and Student Achievement. International Education Studies, 4(1), 198- 201. From: www.eric.ed.gov. No EJ 1066376 (10/11/2016). 
Clark, C. M., \& Peterson, P. L. (1986). Teachers' thought processes. In M. C. Wittrock, (Ed.) Handbook of Research on Teaching (pp. 255-296). NewYork: Macmillan.

Cohen, L., Manion, L., \& Morrison, K. (2007). Educational research methodology (translation by S. Kyranakis, M. Mavraki, C. Mitsopoulou, P. Bithara and M. Filopoulou). Athens: Metaixmio. (in Greek)

Cooper, H. (1985). Models of teacher expectation communication. In J. B. Dusek (Ed.), Teacher expectancies, 136-158. Hillsdale, N.J.: Lawrence Erlbaum. From: www.eric.ed.gov, No ED 374096 (20/10/2019).

Creswell, W. J. (2016). Educational Research: Planning, Conducting, and Evaluating Quantitative and Qualitative Research (Greek translation by Kouvarakou, N., Ed. Ch. Tzorbatzoudis). Athens: ION. (in Greek)

Day, C. (1999). Developing teachers: The challenges of lifelong learning. London/Philadelphia, PA: Routledge/Falmer Press.

Desforges, C. \& Abouchaar, A. (2003). The impact of parental involvement, parental support and family education on pupil achievement and adjustment: A literature review, 433. London: DfES.

Devine, F. (2004). How Parents Help Their Children Get Good Jobs. University of Manchester. Cambridge: University press.

Dimitropoulos, E. (2007). Educational evaluation. Student Assessment. Theory - Practice Problems. Athens: Grigoris. (in Greek)

Fang, Z. (1996). A review of research on teacher beliefs and practices. Educational Research, 38(1), 47-65. doi:10.1080/0013188960380104

Feinberg, W.\& Soltis, J. (1992). School and Society. New York: Teachers College Press.

Fernández-Mellizo, M. \& Martínez-García, J.S. (2017). Inequality of educational opportunities: School failure trends in Spain (1977-2012). International Studies in Sociology of Education, 26(3), 267-287.

Fives, H., \& Buehl, M. M. (2008). What do teachers believe? Developing a framework for examining beliefs about teachers' knowledge and ability. Contemporary Educational Psychology, 33, 134-176.

Flouris G. (2019). School failure: the views of primary school teachers on the causes and ways to deal with it. (Doctoral thesis). School of Education: Department of Pedagogy of Kindergarten Teachers, University of Ioannina. (in Greek)

Fragoudaki, A. (1985). Sociology of education: Theories of social inequality in school. Athens: Papazisis. (in Greek)

Fragoudaki, A. (2001). Social Inequalities and Prejudices and their Relation to the Mass School Failure of Popular Class Origin Students. In: Th. Dragona, E. Skourtou, \& A. Fragoudaki, Education: Cultural Differences and Social Inequalities. Social Identities / Diversities - Social Inequalities, Bilingualism and School. Volume A. Patra: E.A. P. (in Greek) 
Frangoulis, G. (2008). Teachers' perceptions and practices regarding the management of educational inequality and student performance. (Doctoral Thesis), E.K.P.A (NCUA). (in Greek)

Freire, P. (1970). Pedagogy of the Oppressed. New York: Herder and Herder.

Freire, P. (1977). Education for critical consciousness. London: Sheed \& Ward.

Freire, P. (1985). The politics of education culture, power and liberation, trans Macedo. D. Massachusetts: Bergin \& Garvey Publishers, Inc.

Freire, P. (1997). Teachers as cultural workers. Letters to those who dare to teach. Boulder, CO: Westview Press.

Fry, P. S. (1984). Teachers' conceptions of students' intelligence and intelligent functioning: A cross-sectional study of elementary, secondary and tertiary level teachers. International Journal of Psychology, 19. 457-474.

Gardner, H., Kornbacher, M. L. \& Wake, W. K. (1996). Intelligence: multiple perspectives. Fort Worth: Harcourt Brace.

Georgiou, S. N., Stavrinidis, P., \& Panaoura, G. (2002). School failure: causal performance and teacher behavior. Pedagogical Review, 33, 115-136. (in Greek)

Georgiou, S. N., \& Tourva, A. (2006). Classroom stereotypes. In: E. Ftiakas, A. Gagatsis, I. Elias, \& M. Modestou (Eds.), The Modern Educational Research in Cyprus. Proceedings of the 9th Conference of the Cyprus Pedagogical Society (pp. 921-934), June 2-3, 2006, Nicosia: University of Cyprus. (in Greek)

Giavrimis, P., \& Papanis, E. (2008). Sociological Dimensions of School Failure: The Views of Educators and Students of Educational Schools. The Journal of International Social Research, 1(5), 326-354.

Giavrimis, P., Papanis, E., Panitsidou, E. A., \& Papastamatis, A. (2011). Empirical Research on Education and Student Failure: Teachers' Psychological and Sociological Interpretations. International Journal of Humanities and Social Science, 1 (9), 40-47.

Good, T. L. (1982). How teachers' expectations affect results. American Education. 18,25-32.

Heliou, M. (1984). Educational and Social Dynamics, Distribution of educational opportunities, Educational realities, Social dynamics and gender equality. Athens: Poreia. (in Greek)

Jarvis, P. (2001). Adult education at the end of twentieth century in: Jarvis P. (ed.) Twentieth century thinkers in adult and continuing education (Kogan Page, UK).

Kagan, D. M. (1992). Implications of research on teacher beliefs. Educational Psychologist, 27(1), 65-90.

Kalaitzopoulou, M. (2001). The teacher as thinking professional. Athens: Typotheto. (in Greek)

KANEP \& GSEE, (Jan. 2011). The basic figures of Greek education 2010 (primary and secondary education). Athens: C.AN.E.P /G.S.E.E. (in Greek)

Kassotakis, M. I. (2003). Assessing student performance. Means, methods, problems, perspectives. Athens: Grigoris. (in Greek) 
Kassotakis, M. I. (2013). Assessing student performance: Theoretical approaches and practical applications. Athens: Grigoris. (in Greek)

Katsamagou, M. B. (2003). Where teachers and students attribute students' difficulties at school. Pedagogical Review, 35, 115-130. (in Greek)

Katsikas, Ch., \& Kavvadias, G. (2000). Inequality in Greek Education: The Evolution of the Access Opportunities to Greek Education (1960-2000). Athens: Gutenberg. (in Greek)

Katsillis, I., \& Lolou, Ch. (1999). Influence of significant others and educational ambitions. Greek Pedagogical and Educational Research. Athens: Atrapos. (in Greek)

Kelmali, M. (2015). Teachers' views on the profile of the student with low school performance. (Postgraduate Thesis). Patras: E.A.P. (in Greek)

Kelpanidis, M. (1997). Welfare State and education. Equality of opportunities and equality of outcomes: Education as an individual achievement or social benefit. Athens: Kyriakidis. (in Greek)

Kossivaki, F. (1999). School failure: an indication of the pathology of the centralized education system and a possibility of overcoming social exclusion in educational practice. In: Ch. Konstantinou, G. Pleios (ed.), School failure and social exclusion Proceedings of the 8thInternational Scientific Conference. Athens: Ellinika Grammata. (in Greek)

Konstantinou, H. I. (2002). Assessing student performance as pedagogical logic and school practice. Athens: Gutenberg. (in Greek)

Kostaridou - Efklides A. (1999). Motivation Psychology Athens: Ellinika Grammata. (in Greek)

Koutselini-Ioannidou, M. (2008) Structuring and Differentiation of Teaching-Learning in mixed capacity classes: Philosophy and concept. Strategies and Applications. Nicosia: Self-published. (in Greek)

Koutselini, M., \& Pyrgiotakis, I. (2015). Differentiation of teaching and learning. Athens: Pedio. (in Greek)

Lamnias, K. (2002). Sociological theory and education. Distinct approaches. Athens: Metaixmio. (in Greek)

Lampiri - Dimaki, I.- Panagiotopoulos, N. (1995). P. Bourdieu: Sociology of Education. Athens: Kardamitsa-Delfini. (in Greek)

Lappa - Vardouli, K., \& Vardoulis, A. (2006). Social origin and school performance of the student population in the region of Attica. Epistimes Agogis (Educational Sciences): 2, 169-176. (in Greek)

Lariou-Drettaki, M. (1993). Abandonment of compulsory education and factors related to it. Athens: Grigoris. (in Greek)

Lykidi, SF (2012). Teachers' perceptions for their students and their expectations for school performance. A research approach to culturally diverse students. (Postgraduate paper). University of Patras (in Greek)

Lynott, D.-J., \& Woolfolk, A. E. (1994). Teachers' implicit theories of intelligence and their educational goals. Journal of Research $\mathcal{E}$ Development in Education, 27(4), 253-264. 
Matsagouras, H. G. (2001). Teaching Strategies: Critical Thinking in Teaching Practice. Athens: Gutenberg. (in Greek)

Matsagouras, H. G. (2004). Theory and Practice of Teaching, B '. Teaching Strategies. Athens: Gutenberg. (in Greek)

Matsagouras, H. G. (2006). Theory of teaching: personal theory as a framework for reflexivecritical analysis. Athens: Gutenberg. (in Greek)

Mezirow, J. (1998). On Critical Reflection. Adult Education Quarterly, 48, 185-198.

Mezirow, J. (2009). An Overview on Transformative Learning. In Illeris, K. (Ed.), Contemporary Theories of Learning. London and New York: Routledge, pp. 90105.

Milios, G. (1993). Education and Power. Athens: Critical Scientific Library. (in Greek)

Mylonas Th. \& Dimitriadis A. (1999). From inequality to school to exclusion in the classroom. In: Pedagogical Society of Greece - School of Education, University of Ioannina (pp. 385-408), School failure and social exclusion, causes, consequences, treatment, curators: Ch. Konstantinou, G. Pleios, Proceedings of the 8th scientific conference, Athens: Ellinika Grammata. (in Greek)

Mylonas, Th. (1993). Social reproduction in school: Theory and Experience. Athens: Armos. (in Greek)

Mylonas, Th. (2004). The Reproduction of Social Classes through School Mechanisms - The Secondary Education in the Village and in the City. Athens: Gutenberg. (in Greek)

Nespor, J. (1987). The role of beliefs in the practice of teaching. Journal of Curriculum Studies, 19 (4), 317-328.

Niari, M. (2013). The Pygmalion phenomenon in Distance Education. The case of the 'Studies in Education' program of EAP. Patras: E.A.P. Retrieved 15-11-2019, from https://apothesis.eap.gr/handle/repo/25552. (in Greek)

Noutsos, M. (2003). Unified Curriculum Framework: the ideology of "akhtarma", Educational Community, 67, 24-29. (in Greek)

Pagoni, B. (2017). Teachers' views on school failure and their connection with educational practice: Quantitative research (Diploma Thesis: Studies in Education). Patras: E.A.P. (in Greek)

Pajares, M. F. (1992). Teachers' Beliefs and Educational Research: Cleaning Up a Messy Construct. Review of Educational Research, 62(3), 307-332. From, http://www.jstor.org/stable/1170741. ( 12/12/2019).

Papakonstantinou, P. (1981). Inequality in Greek Compulsory Education. School and Social Origin.O Politis Magazine, 44, 46-51. (in Greek)

Patereka, H. (1986). Basic concepts of Pierre Bourdieu and Jean Claude Passeron in sociology of education. Thessaloniki: Kyriakidis Bros. (in Greek)

Poimenidou, D. (2009). The teacher's personal theory: a theoretical and empirical approach. Thessaloniki: Kyriakidis Bros. (in Greek)

Pyrgiotakis, E. I. (2006). Introduction to pedagogical science. Athens: Pedio. (in Greek) 
THE ROLE OF TEACHERS' VIEWS ON SCHOOL PERFORMANCE IN THEIR TEACHING APPROACH AND THEIR RELATIONSHIPS WITH STUDENTS: THE CASE OF MOUNTAINOUS AREAS AND PERIPHERY SECONDARY SCHOOL TEACHERS IN THE PREFECTURE OF ILIA, GREECE

Rekalidou, G. (2011). Assessment of learning and assessment for learning. Student Performance as Pedagogical and School Logic. Athens: Pedio. (in Greek)

Reynolds, D. (2007). Restraining Golem and Harnessing Pygmalion in the Classroom: A Laboratory Study of Managerial Expectations and Task Design. Academy of management Learning EEducation. 6(4), 475-483. Retrieved 10-1- 2020, from amle.aom.org

Rist, R. C. (2000). Student social class and teacher expectations: the self-fulfilling prophecy in ghetto education. Harvard Educational Review: 70(3), 257-301. http://faculty.washington.edu/rsoder/EDUC305/310RistHarvardEdReview.pdf.

Robson, C. (2010). Real World Research. Athens: Gutenberg. (in Greek)

Sharp, R., \& Green, A. (1978). Education and Social Control. London: Routledge.

Sipitanou, A. (1992). Selection mechanisms in the Greek educational system (1834-1985). (Doctoral thesis). A.P.TH (AUTh). (in Greek)

Sotiropoulou, K. (1998). Representations of teachers in technical and Vocational education: Social inequalities and pedagogical principles in the Technical - Vocational High School. The concepts of learning, discipline and adaptation. (Doctoral Thesis), E.K.П.A (NCUA). (in Greek)

Sprouse, J., \& Webb J. (1994). The Pygmalion Effect and Its Influence on the Grading and Gender Assignment on Spelling and Essay Assessments, No ED 374096. Retrieved 20/10/2019 from www.eric.ed.gov

Trouilloud, D., \& Sarrazin, P. (2003). Les connaissances actuelles sur l' effet Pygmalion: processus, poids et modulateurs. Revue Française de Pédagogie, 145, 89-119 hal.archives-ouvertes.fr.

Tsoukalas, K. (1992). Dependence and Reproduction. The Social Role of Educational Mechanisms in Greece (1830-1922). Athens: Themelio (in Greek)

Tzani, M. (2004) Sociology of Education. Athens: Grigoris. (in Greek)

Vaikousi-Vergidou, D. M. (1994). Teachers' attitudes towards children with school difficulties in writing and reading in the first three grades of primary school. (Doctoral thesis). Aristotle University, Thessaloniki. (in Greek)

Vareltzi, E. \& Giavrimis, P. (2018). Students with low school performance and the theory of "label". Educational Sciences, 1, 137-151. Retrieved 21-11-19, from https://ejournals.lib.uoc.gr/index.php/edusci/article/download/311/248/.

(in Greek)

Visscher, A. J. \& Coe, R. (2003). School performance feedback systems: conceptualisation, analysis, and reflection. School effectiveness and school improvement, 14, 321-349.

Weiner, B. (1994). Integrating Social and Personal Theories of Achievement Striving. Review of Educational Research, 64(4), 557-573.

Xochellis, P. (2000). The educational work as a social role: A research on the self-perception and the attitudes of Greek teachers. Thessaloniki: Kyriakidis Bros. (in Greek) 
Xochellis, P. (2005). The teacher in the modern world: his role and professional profile today, the education and the evaluation of his work. Athens: Typothito-Dardanos. (in Greek)

Yero, J, L. (2002). Teaching in Mind: How Teacher Thinking Shapes Education. Hamilton, Montana: MindFlight Publishing.

Zapanioti, N. (2019). The views of Primary Education teachers on the relationship between social inequality and school performance. (Graduate Thesis. Education: Cultural differences and social inequalities). Patras: EAP. (in Greek). 

to copy, distribute, transmit or adapt the article content, providing a proper, prominent and unambiguous attribution to the authors in a manner that makes clear that the materials are being reused under permission of a Creative Commons License. Views, opinions and conclusions expressed in this research article are views, opinions and conclusions of the author(s). Open Access Publishing Group and European Journal of Education Studies shall not be responsible or answerable for any loss, damage or liability caused in relation to/arising out of conflicts of interest, copyright violations and inappropriate or inaccurate use of any kind content related or integrated into the research work. All the published works are meeting the Open Access Publishing requirements and can be freely accessed, shared, modified, distributed and used in educational, commercial and non-commercial purposes under a Creative Commons Attribution 4.0 International License (CC BY 4.0). 